$$
\begin{aligned}
& \text { 震 }
\end{aligned}
$$

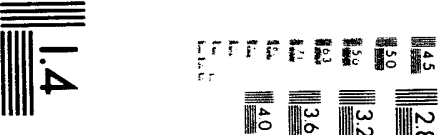

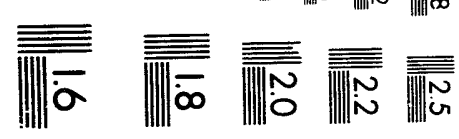



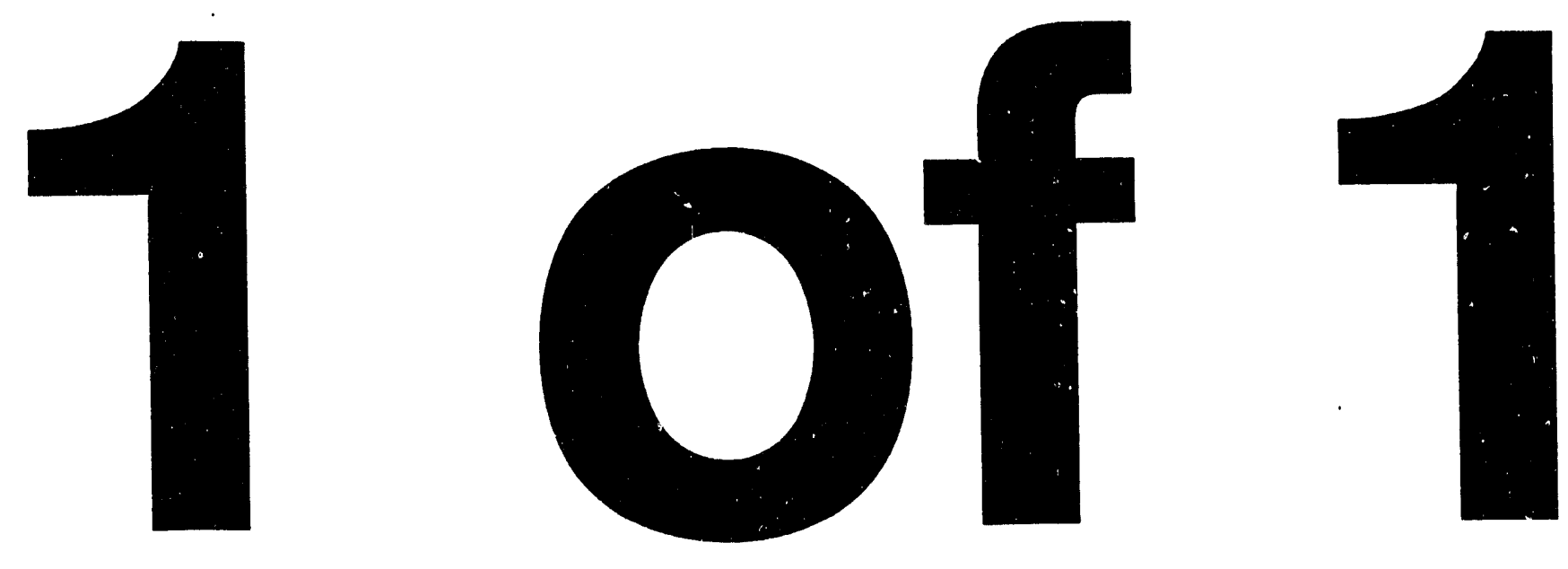


\section{.893950}

UCRL-ID- 114727

Vanadium Tube Processing and Analysis

D. D. Kautz

G. J. Tanaka

August 11, 1993

This is an informal report intended primarily for internal or limited external distribution. The opinions and conclusions stated are those of the author and may or may not be those of the Laboratory.

Work performed under the auspices of the U.S. Department of Energy by the Lawrence Livermore National Laboratory under Contract W-7405-Eng-48.

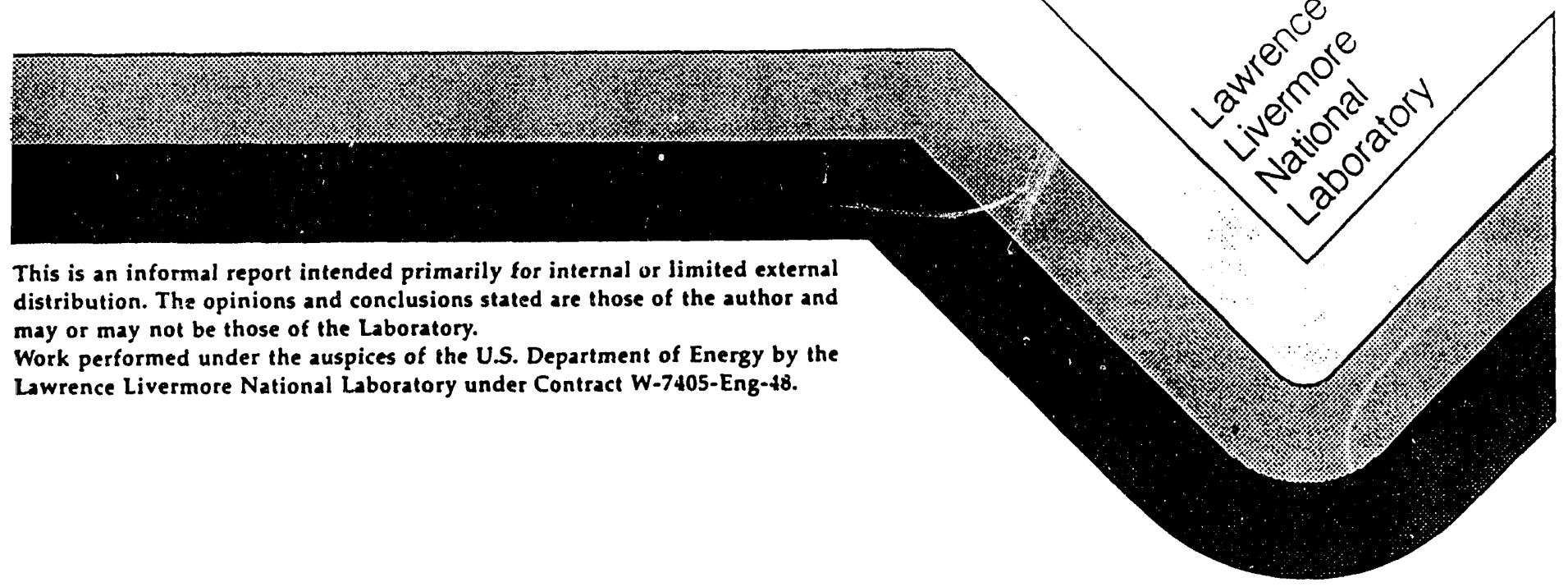




\section{DISCLAIMER}

This document was prepared as an account of work sponsored by an agency of the United States Government. Neither the United States Government nor the University or California nor any of their employees, makes any warranty, express or implied, or assumes any legal liability or responsibility for the accuracy, completeness, or usefulness of any information, apparatus, product, or process disclosed, or represents that its use would not infringe privately owned rights. Reference herein to any specific commercial products, process, or service by trade name, trademark, manu facturer, or otherwise, does not necessarily constitute or imply its endorsement, recommendation, or favoring by the Uniled States Government or the University of California. The views and opinions of authors expressed herein do not necessarily state or reflect those of the United States Government or the University of California, and shall not be used for advertising or product endorsement purposes.

This report has been reproduced directly from the best available copy.

Available to DOE and DOE contractors from the Office of Scientific and Technical Information P.O. Box 62, Oak Ridge, TN 37831

Prices available from (615) 576-8401, FTS 626.8401

A vailable to the public from the National Techaical Information Service

U.S. Department of Commerce 5285 Port Royal Rd. Springfield, VA 22161 


\title{
Vanadium Tube Processing and Analysis
}

\author{
D.D. Kautz \\ G. J. Tanaka
}

\section{Summary}

Vanadium tubing obtained from Century Tubes, a custom tubing manufacturer, was studied to determine as-received quality and fabricability. Applications for this tubing involve crimping and sealing operations at Pantex Plant requiring very high levels of leak-tightness (leak rates less than $10^{-8}$ atm-cc He/sec). The as-received material had poor OD and ID surface finish and cleanliness that needed to be improved before use in component fabrication.

Savannah River Technical Center (SRTC) personnel developed a cleaning procedure to make this tubing acceptable for crimping and sealing operations. After suitably cleaning the tubing, we tested several tube sealing techniques and all showed some degree of success. Pantex Plant personnel are now implementing a tube sealing process very similar to one of the techniques studied, a mechanical crimp followed by seal welding.

\section{Introduction}

This report covers the development of several different processes for the cleaning and sealing of vanadium tubing. The tubing that we studied was produced by Century Tubes in San Diego, CA from vanadium bar stock supplied by LLNL. The vanadium bar stock met LLNL specification RM255525. A metallographic crosssection of this bar stock showing its fine grain size and overall quality is found in Figure 1.

We found that acceptable tube seals were made easily if the tubing was clean and free from defects. This led to the development of cleaning procedures to remove a tenacious oxide layer and reduce the severity of laps on the tubing ID. After proper cleaning, several tube sealing techniques were tested and showed varying degrees of success. Sealing techniques that we used included: 1) resistance pinch welding, 2) GTA welding with an orbital weld head attachment and 3) mechanical crimping followed by gas tungsten arc (GTA) weld sealing. After sealing, the tubes were parted into a seal side and a throw-away side. The seal side stayed with each fabricated part for long-term use, while the throw-away side only had to remain sealed until valving on gas transfer systems could be closed. Each technique had advantages and disadvantages when considered for the final application. Starting with cleaning, we will discuss each portion of the study separately and then compare all of the techniques. 


\section{Tube cleaning}

As-received vanadium tubing had a tenacious oxide layer on the ID surface, as shown in the SEM photomicrograph in Figure 2. Using energy dispersive spectroscopy (EDS) techniques on a scanning electron microscope (SEM), we found this layer to be vanadium oxide with traces of elements normally found in tube drawing lubricants. We believe that the tenacity of the layer was caused by reaction between the vanadium tubing and contaminants left inside the tubing (drawing lubricant and inadequate purging of reactive gases) during the annealing cycles performed between drawing operations.

Both the ID and OD of the tubing exhibited lap defects, as shown in the transverse and longitudinal metallographic cross-sections in Figure 3. These defects were caused by machining procedures used to form the tube blank. The vanadium bar stock was gun-drilled to form the ID surface of each tube blank. After gun-drilling, the OD surface was lathe-turned to make the OD concentric to the ID. The poor machinability of vanadium and non-optimized machining procedures caused the material to smear during these operations. The lap defects probably were very small after machining and then elongated during tube drawing.

Cleaning studies were initiated at SRTC after discovering the surface oxidation problem. SRTC personnel had cleaned stainless steel tubing for other programs and studied a similar technique to clean the vanadium tubing. This technique employed pumping an acidic solution through the tubing which etched the surface clean. The solution was a mixture of water, nitric acid $\left(\mathrm{HNO}_{3}\right)$ and a commercial etchant called Nitradd (produced by Turco Products in Carson, CA). The Nitradd etchant contains acetic acid $\left(\mathrm{CH}_{3} \mathrm{CO}_{2} \mathrm{H}\right)$ and ammonium bifluoride $\left(\mathrm{NH}_{4} \mathrm{~F}_{2}\right)$ as active ingredients.

A matrix was devised using short lengths of tubing approximately 1 to 2 inches long. This length was sufficient for crimping and welding studies. Two variables were allowed in the study: 1) the strength of cleaning solution and 2) the length of cleaning time. Table 1 shows the matrix of parameters SRTC studied to determine the best cleaning practice for this tubing. It was determined that a solution consisting of $80 \%$ water, $12 \%$ nitric acid and $8 \%$ Nitradd removed tre oxide layer without adversely affecting the base material. A cleaning time of 5 minutes was sufficient to clean the short lengths of tubing used in this study. Figure 4 shows a SEM photomicrograph of the tubing ID cleaned using the most successful parameters.

After the initial cleaning study was completed, we also needed lengths of tubing approximately 12 inches and 26 inches long to meet programmatic needs. We found that the 5 minute cleaning time was insufficient to remove all oxide from the tubing surface. Further studies revealed that increasing the time to 8 minutes for the 12 inch lengths and 15 minutes for the 26 inch lengths allowed for satisfactory cleaning. In both cases, the solution was pumped from one end for half of the 
time, then the ends of the tube were switched and the cleaning cycle was completed. Figure 5-a shows a SEM micrograph of partially cleaned tubing from a 12 inch length using the 5 minute cleaning cycle. Figure 5-b shows fully cleaned tubing from the midsection of a 26 inch length of tubing.

Allied Signal Aerospace - Kansas City Division (ASA-KCD) studied four other cleaning methods on short lengths of tubing to determine their viability. Solutions that they used included: 1) Dynadet cleaner (an alkaline detergent made by Oakite), 2) aqua regia solution (nitric acid and hydrochloric acid ( $\mathrm{HCl}$ ) mixture), 3) sodium hydroxide solution $(\mathrm{NaOH})$ and 4) concentrated nitric acid. The quality of the cleaned surfaces was analyzed using a SEM. Figure 6 shows the surface quality attained by each cleaning process.

The specimen cleaned with the Dynadet detergent, Figure 6-a, was only slightly different from the as-received tubing. Some loose particles were removed, but the baked-on layer of oxide remained. The specimen cleaned for 15 seconds with aqua regia, Figure $6-b$, looked very similar to specimens from the Nitradd cleaning process that were not fully cleaned. This solution looked promising for cleaning vanadium, although longer tubing lengths need to be evaluated. The specimen cleaned for 1 minute with sodium hydroxide, Figure 6-c, also looked similar to specimens partially cleaned with the Nitradd solution. On visual inspection, however, the ID of the tubing looked to be reacting with the solution to form other surface contaminants. These reaction products need to be studied further before the sodium hydroxide solution is considered acceptable. The specimen cleaned for 15 seconds with concentrated nitric acid, Figure 6-d, was very pitted from the cleaning process. This solution looks to be too aggressive for the cleaning of vanadium tubing.

\section{Confined-pinch resistance welding}

The first sealing technique considered for vanadium tubing was confined-pinch resistance welding. Two matrices of welds were performed by SRTC personnel during this study. The first set of welds was done using as-received tubing and the second set of welds was done on cleaned tubing.

The first set of welds consisted of 19 specimens. Table 2 lists the parameters used in making each weld in the first matrix. A general poor quality was found in these welds that was due to the oxide layer present at the weld interface. The oxide on the ID surface diffusion-bonded during the welding process, but did not break down fully to allow formation of an acceptable quality weld nugget. Figure 7-a shows a typical metallurgical cross-section from this weld development matrix, and Figure 7-b a cross-section of the best weld in the matrix. The weld in Figure 7-a has a considerable amount of oxide present at the weld interface. The weld in Figure 7-b started to form an acceptable weld nugget. 
All welds were burst tested and dimensionally inspected before metallurgical examination was done. All tubes burst in the base metal tubing. Scatter in the data is due to the short, random lengths of tubing used in the study which allowed the high pressure fittings to add structural support in varying degrees to the tubing. Burst test results are recorded in Table 3 and a macrograph of a typical specimen is shown in Figure 8.

Dimensional inspection showed that while the design of confinement anvils had not been optimized for this size of tubing, all welds were confined to within specification. The as-received vanadium tubing OD was nominally $0.092^{\prime \prime}$ with a 0.025 " wall thickness. The finished parts had to fit coaxially inside another tube measuring $0.105^{\prime \prime}$ ID. The largest diametral dimension measured on any tube after welding was $0.095^{\prime \prime}$. This dimension was controlled mainly by the dimensions of the confinement anvils. The material displacement in the weld nugget (wall thickness minus weld nugget thickness) was a maximum of $0.009^{\prime \prime}$. The displacement dimension was controlled by a combination of the welding parameters and the dimensions of the confinement anvils.

The second matrix of welds consisted of five welding parameter conditions. These included the best set, as determined metallographically, and the four most extreme parameter conditions, all chosen from the first matrix. In this second matrix, each parameter set produced a satisfactory weld nugget. Figure 9 shows a typical weld cross-section from this matrix. We found that as long as the ID wall of the vanadium tubing was cleaned sufficiently, a very large window of welding parameter space produced acceptable confined-pinch, resistance welds. Dimensional inspection on the second matrix was of a "go/no-go" nature with all welds meeting the requirements. None of the welds in the second matrix was burst tested due to the excellent results from the first matrix.

The advantages of confined-pinch, resistance welding are that: 1) negligible tube wall thinning occurs in the weld affected area; and 2) welding of the interior interface is completed while no melting occurs at the OD surface. The disadvantages are that: 1) cutting the tubing after welding may generate fine particulate waste; and 2) it is difficult to ensure both the seal and throw-away ends of the tubing are satisfactorily sealed after the cutting operation.

\section{GTA - Orbital Tube Welding Head}

A tube sealing technique which employed the use of a gas tungsten arc welding machine with an orbital tube welding head was studied by Pantex Plant personnel. In this technique, the electrode is revolved perpendicular to the axis of the tubing to melt through the tube wall. A small load is applied axially during the welding cycle which pulls the tubing apart. Surface tension forces in the molten vanadium then draw the material together to seal both ends of the tubing. 
Due to the thermal properties and chemical purity of vanadium, a large fusion zone and heat-affected zone (HAZ) are associated with this arc welding process. These properties also cause the weld-affected areas to have very large grain size, in many cases a single grain extends from the ID surface to the OD surface.

Because of the large volume of weld affected material, inert gas shielding becomes extremely important in the weld area since molten vanadium is very reactive with many atmospheric gases, including oxygen, nitrogen and carbon dioxide. Argon was used to shield the weld pool and solidifying metal during the welding cycle.

Figure 10 shows cross-sections of two seal welds made using this technique. The weld shown in Figure 10-a had an argon back purge through the tubing. This weld had very little porosity and showed good ductility as measured by a Vickers microhardness test, nominally $220-250 \mathrm{DPH}$ in the weld versus $140-150 \mathrm{DPH}$ in the base tubing.

The weld shown in Figure 10-b had a carbon dioxide back purge through the tubing. This weld was much harder than the first as shown by a large difference in microhardness between the weld and the base tubing, nominally 350-390 DPH in the weld versus 140-150 DPH in the base tubing. This weld also had a great deal of porosity. Both effects were caused by the dissociation of the carbon dioxide by the molten vanadium. The increased hardness was caused by precipitation of vanadium carbide during solidification of the vanadium weld metal. The porosity was caused by having a higher than equilibrium concentration of oxygen present in the weld metal, causing oxygen gas to be evolved during the cooling cycle.

The advantages of GTAW with an orbital weld head are that: 1) it is a one step process to both seal and part the tubing; and 2) the equipment to perform this technique is already in place at Pantex Plant. The disadvantages are that: 1) a large amount of material is deleteriously affected by the welding process; and 2) dimensional control of the final tube length is not well-controlled.

\section{Mechanical Crimp - GTA Weld Seal}

A sealing technique developed for stainless steel tubing at RFP was studied to determine whether it could be applied to vanadium tubing. This two step process included a mechanical crimp followed by a GTA weld sealing operation. The structural integrity of the seal made by this technique is maintained by the mechanical crimp. The weld seal provides only a secondary seal and also smooths the very sharp edges left by the crimping operation. Therefore, most testing was done on as-crimped specimens with only a small amount of the study devoted to welded specimens.

We tested several crimped specimens for leak-tightness and pressure bearing capability. It was desirable that both sides of the crimp be leak-tight to ensure that proper gas pressures could be maintained within the tubing. Therefore, we studied both the seal and throw-away sides of the crimp. Requirements were different for 
the two sides. The seal side was required to maintain leak-tightness to less than $10^{-8} \mathrm{~atm}-\mathrm{cc} \mathrm{He} / \mathrm{sec}$ while pressurized at $1 \mathrm{ksi}$ internally. The throw-away side was required only to be leak-tight at approximately ambient pressure conditions.

We destructively tested several mechanically crimped tubing specimens, including: 1) as-received tubing, 2) SRTC procedure, partially-cleaned tubing, 3) SRTC procedure, fully-cleaned tubing, 4) mechanically-cleaned (reamed using a lathe) tubing and 5) all of the ASA-KCD cleaned tubing. A typical cross-section from a mechanical crimp with a GTA seal weld is shown in Figure 11. The mechanical crimp interface is much larger than the weld nugget and shows no signs of being disturbed by the welding process.

All tubes easily surpassed the leak-tightness requirements, although a large amount of scatter was found in the results. This scatter was probably caused by not using fully-optimized crimp tooling. One burst specimen failed at a very low pressure. SEM photomicrographs showed the failure to be caused by a defect in the tube wall probably caused by either a lap or the very aggressive nitric acid cleaning process used on this specimen. All other specimens far exceeded requirements for their respective seals. Table 4 lists the results of all burst tests on the as-crimped specimens.

Figure 12 shows the various failure modes found during burst testing. Figure 12-a shows a typical seal side crimp after burst testing. Failure occurred in the area of greatest wall thinning caused by the crimping operation. Figure 12-b shows a typical throw-away side crimp after burst testing. Again, failure occurred in the area of greatest wall thinning in the tubing. Figures $12-\mathrm{c}$ and $12-\mathrm{d}$ show the failure mode in the low burst test specimen. The crimp failed both in the normal failure axis and along the drawing direction of the tubing. No embrittlement was detected as shown by the flap of material found at the point of failure that was folded 180 degrees by the pressure release.

Some GTA seal welds were made on tube crimps to determine whether the HAZ of the weld was detrimental to the mechanical crimp. We had three concerns with a large weld HAZ: 1) reaction of the gas inside the tubing with hot vanadium weld metal could cause embrittlement, 2) large grains in the HAZ could allow for high diffusion rates along grain boundaries and 3) annealing of the HAZ material could allow failures to occur at very low pressures. By use of a copper heatsink, the HAZ was controlled very well and ro reduction in the integrity of the crimp was found. Figure 13-a shows a SEM photomicrograph of a GTA seal weld surface and Figure 13-b a metallurgical cross-section showing the fusion zone, related HAZ and mechanical crimp.

The advantages of mechanical crimping and GTAW sealing are that: 1) it has a long history of success for similar tubing designs in stainless steel alloys; and 2) it easily seals both tube faces making pressure stabilization problems unlikely. The 
disadvantages are that: 1) it is a two step process; and 2) the burst strength properties of the tubing are reduced due to wall thinning from the mechanical crimping operation.

\section{Conclusions}

1. A satisfactory acid solution (nitric acid, Nitradd, and water) cleaning procedure was developed which allows cleaning of tubing lengths up to 26". Four other cleaning solutions were studied on very short lengths of tubing and only an aqua regia cleaning procedure proved viable for evaluation with longer tubing lengths.

2. Surface contamination and reactive gases have a major negative effect on the weldability of vanadium tubing.

3. In appropriate situations, any of the studied crimping and sealing operations may be acceptable for sealing of vanadium tubing. Each operation has advantages and disadvantages to be considered for a given application. With further parameter and tooling optimization, we believe that all of the techniques discussed here can achieve still better results.

\section{Recommendations}

1. We suggest for the work at Pantex Plant, that all t' !bing should be cleaned using the processing developed at Savannah River Technology Center. Specific cleaning times will need to be developed for the appropriate lengths of tubing, but the solution seems to work very woll on this material.

2. We suggest that the mechanical crimping followed by seal welding is the most appropriate sealing technology for the operations at Pantex Plant. In this case, the overiding concern is that both sides of the seal are leak-tight.

\section{Acknowledgments}

This report is a compilation of work done throughout the DOE weapons complex. We wish to thank the following, who provided samples and data for this work:

1. Jim Morin at Savannah River Technical Center provided welding and cleaning support,

2. Dan Orr and Dave Jarboe at Pantex Plant provided welding and technical support, as well as samples from ASA-KCD,

3. Tom Glenn at Rocky Flats Plant provided welding and mechanical crimping support, and

4. At LLNL, Jerry Russell provided leak and burst testing support and Bob Kershaw and Jim Yoshiyama provided metallographic support.

This work would not have been possible without their talents and we sincerely thank them all. 


\section{Table 1}

\section{SRTC Vanadium Tube Cleaning Matrix}

$\begin{array}{cccccc}\text { Specimen } & \begin{array}{c}\text { Nitric Acid } \\ \text { (vol \%) }\end{array} & \begin{array}{c}\text { Nitradd } \\ \text { (vol \%) }\end{array} & \begin{array}{l}\text { Water } \\ \text { (vol \%) }\end{array} & \begin{array}{l}\text { Cleaning Time } \\ \text { (minutes) }\end{array} & \text { Result 1 } \\ 1 & 6 & 4 & 90 & 1 & \text { C } \\ 2 & 6 & 4 & 90 & 5 & \text { C } \\ 3 & 12 & 8 & 80 & 1 & \text { C } \\ 4 & 12 & 8 & 80 & 5 & \text { A } \\ 5 & 24 & 16 & 60 & 1 & \text { A } \\ 6 & 24 & 16 & 60 & 5 & \text { B }\end{array}$

1 - Cleaning results are as follows:
A: satisfactory cleaning
B: overetched vanadium / tapering at tube ends
C: incomplete cleaning 


\section{Table 2}

Parameters Used in Confined-Pinch, Resistance Welding of Vanadium

$\begin{array}{lccccc}\text { Sample } & \text { Voltage } & \begin{array}{l}\text { Electrode } \\ \text { Force } \\ \text { (lbs.) }\end{array} & \begin{array}{l}\text { Piston } \\ \text { Pressure } \\ \text { (psig) }\end{array} & \begin{array}{l}\text { Duffer }{ }^{1} \\ \text { (volts) } \\ \text { (amperes) }\end{array} & \begin{array}{l}\text { Weld } 2 \\ \text { Time } \\ \text { (cycles) }\end{array} \\ 12441 & 350 & 1000 & 87 & 3960 & 12 \\ 12442 & 350 & 800 & 71 & 3900 & 12 \\ 12443 & 350 & 600 & 55 & 3840 & 12 \\ 12444 & 350 & 400 & 41 & 3770 & 12 \\ 12445 & 350 & 1200 & 103 & 3920 & 12 \\ 12446 & 350 & 1400 & 119 & 3930 & 12 \\ 12447 & 350 & 1000 & 87 & 3910 & 12 \\ 12448 & 380 & 1000 & 87 & 4370 & 12 \\ 12449 & 400 & 1000 & 87 & 4600 & 12 \\ 12450 & 420 & 1000 & 87 & 4990 & 12 \\ 12451 & 450 & 1000 & 87 & 5450 & 12 \\ 12452 & 400 & 1000 & 87 & 4670 & 12 \\ 12453 & 400 & 800 & 71 & 4630 & 12 \\ 12454 & 380 & 900 & 79 & 4380 & 12 \\ 12455 & 380 & 850 & 75 & 4360 & 12 \\ 12456 & 380 & 800 & 71 & 4350 & 12 \\ 12457 & 380 & 900 & 79 & 4360 & 12 \\ 12458 & 380 & 850 & 75 & 4360 & 12 \\ 12459 & 380 & 800 & 71 & 4350 & 12\end{array}$

1 - Duffer current is the current measured by a Duffer's high current ammeter.

2 - Weld time is measured in cycles, which are $1 / 60$ second. 
Table 3

Confined-Pinch, Resistance Weld Burst Test Results

$\begin{array}{lcc}\text { Sample } & \begin{array}{c}\text { Leak-Tight to } \\ 10^{-8} \text { atm cc He/sec }\end{array} & \begin{array}{c}\text { Burst Pressure } \\ (\mathrm{ksi})\end{array} \\ 12441 & \text { yes } & 42.2 \\ 12442 & \text { yes } & 42.2 \\ 12443 & \text { yes } & \\ 12444 & \text { yes } & 41.5 \\ 12445 & \text { yes } & 43.1 \\ 12446 & \text { yes } & 41.0 \\ 12447 & \text { yes } & 44.4 \\ 12448 & \text { yes } & 36.1 \\ 12449 & \text { yes } & 36.2 \\ 12450 & \text { yes } & 37.5 \\ 12451 & \text { yes } & 34.2 \\ 12452 & \text { yes } & 36.6 \\ 12453 & & 41.6 \\ 12454 & \text { yes } & 41.4 \\ 12455 & \text { yes } & 36.5 \\ 12456 & \text { yes } & 35.6 \\ 12457 & \text { yes } & 35.7 \\ 12458 & & 34.0 \\ 12459 & \text { yes } & 34.2 \\ & \text { yes } & 35.6 \\ & & \end{array}$


Table 4

Mechanical Crimp Burst Test Results

Cleaning

Technique

Dynadet

Aqua Regia

Sodium Hydroxide

Nitric Acid

Machined

As-received

As-received

Nitradd

Nitradd

Nitradd

Nitradd
Crimp Side

seal

seal

seal

seal

seal

seal

throw-away

seal

seal

seal

throw-away
Leak-Tight to

$<10^{-8} \mathrm{~atm} \mathrm{CC} \mathrm{He} / \mathrm{sec}$

yes

yes

yes

yes

yes

yes

yes

yes

yes

yes

yes
Burst Pressure

(ksi)

11.7

13.1

12.7

$<2$

8.2

8.3

15.0

7.7

9.0

8.0

15.5 


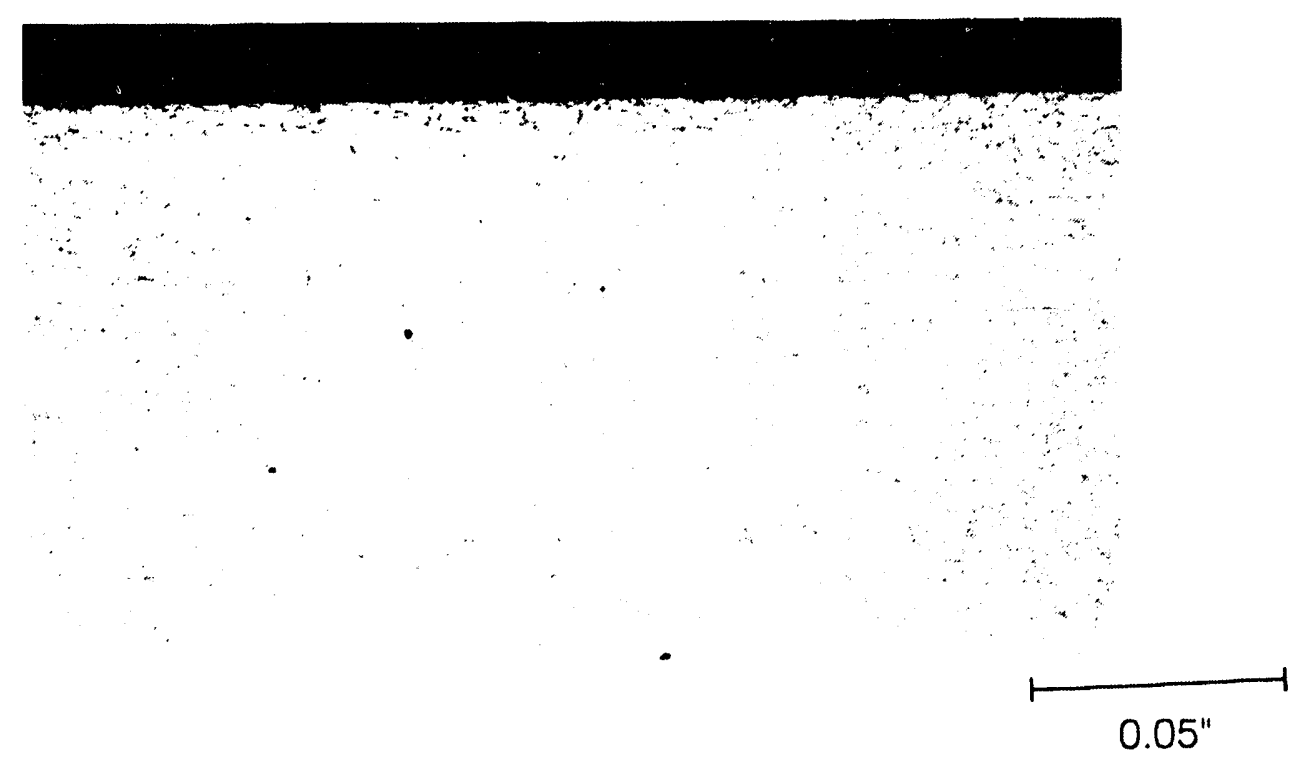

Figure 1. Longitudinal metallographic cross-section of as-received vanadium bar stock. No laps on the OD surface or internal defects were noted. Material has fine, slightly elongated grains from a highly controlled bar reduction and annealing schedule.

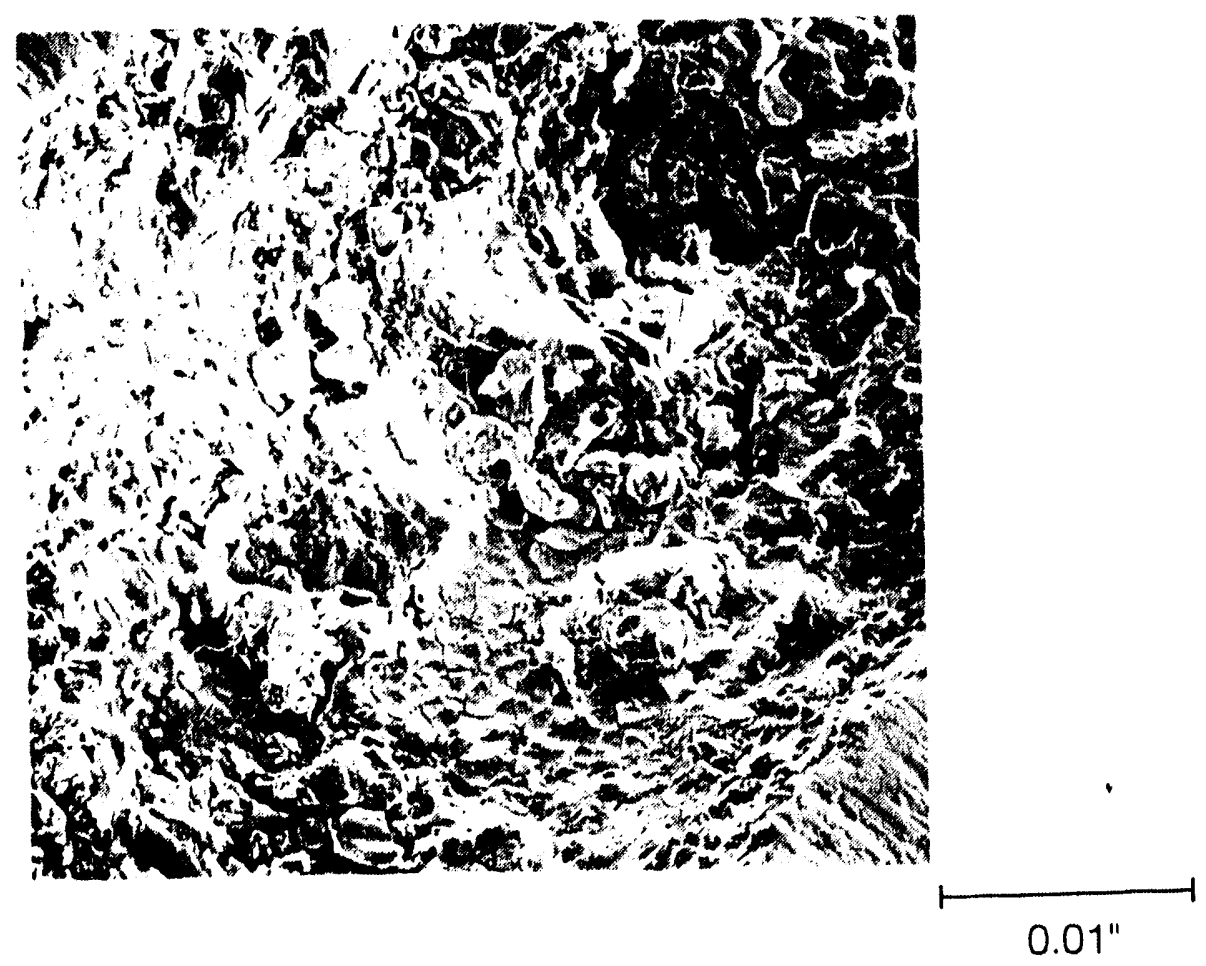

Figure 2. SEM photomicrograph of the ID of as-received vanadium tubing. The oxide layer that we found was rough and very adherent to the tube wall. 


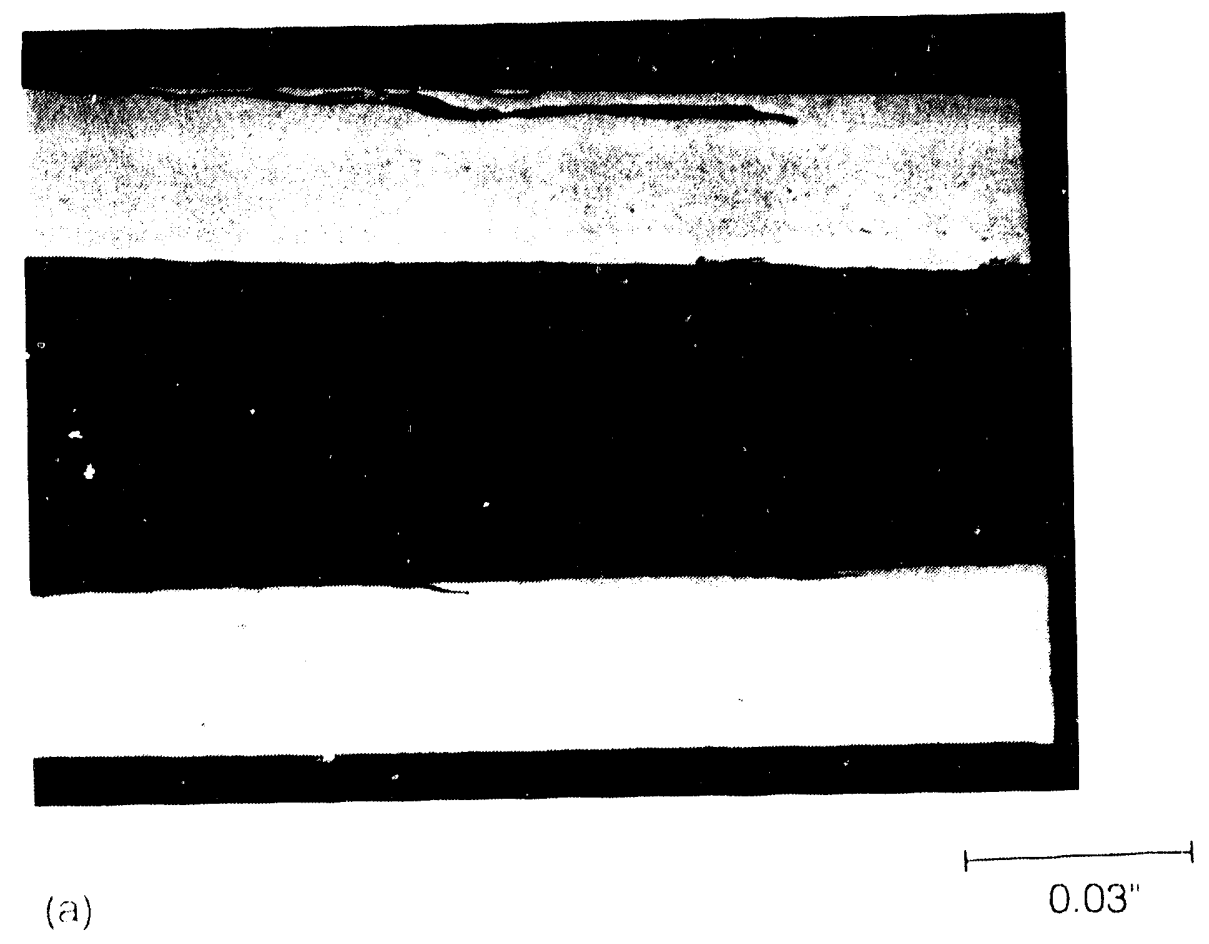

(a)

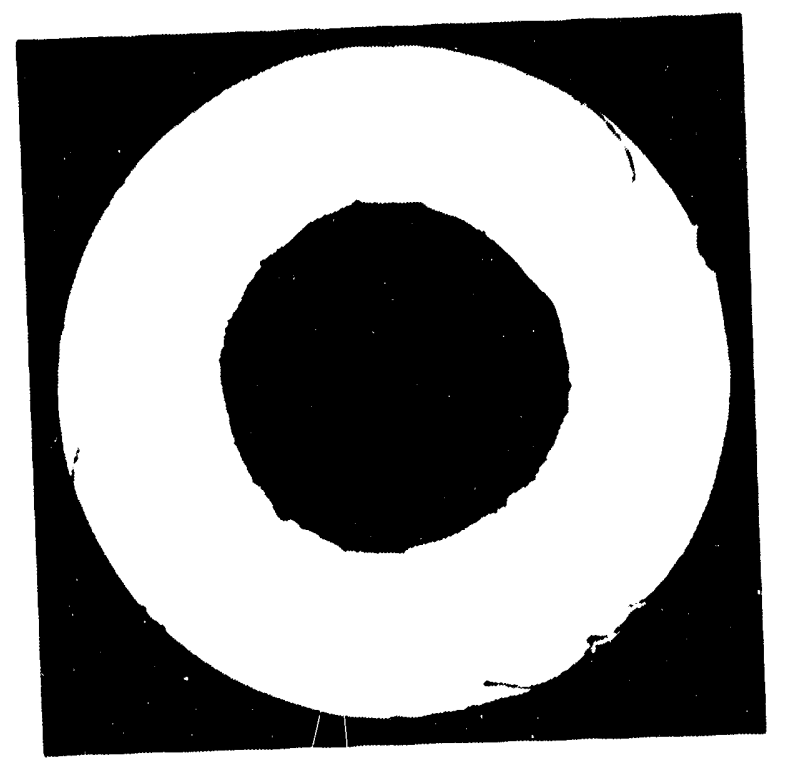

(b)

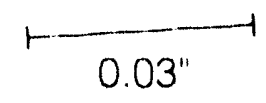

Figure 3. Longitudinal (a) and transverse (b) metallographic cross-sections of the as-received vanadium tubing. Note the laps on both $O D$ and ID surfaces. 


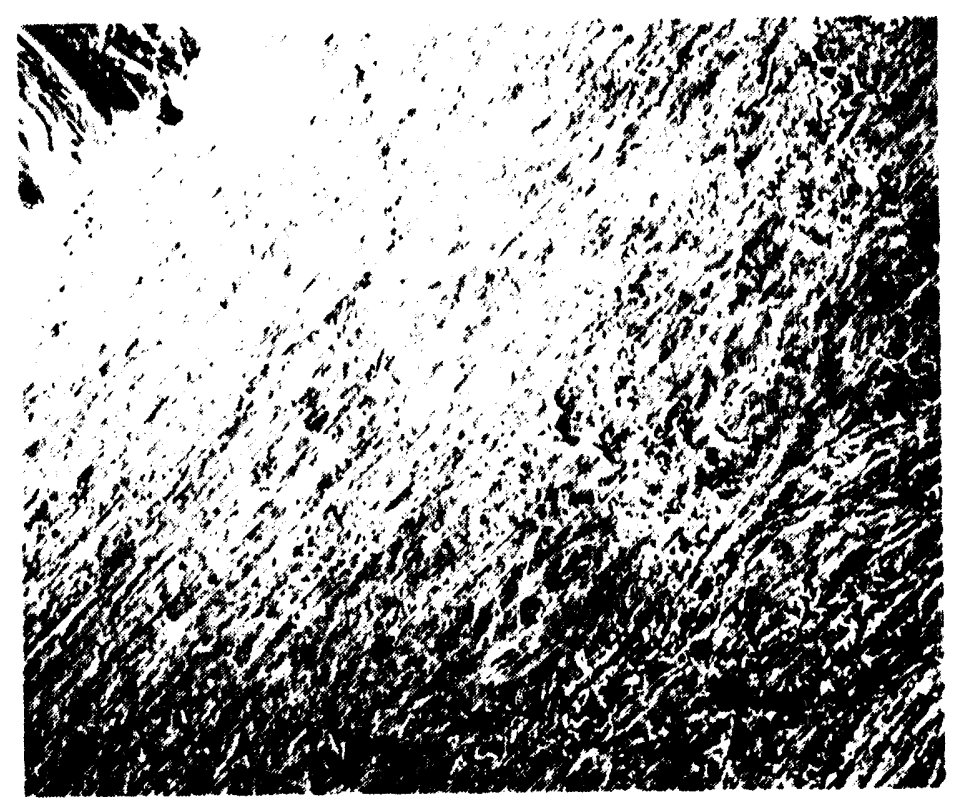

$0.01^{\prime \prime}$

Figure 4. SEM photomicrograph of the ID of vanadiurn tubing after Nitradd cleaning process. The rough oxide layer has been removed, but note that lap features have not been fully removed.

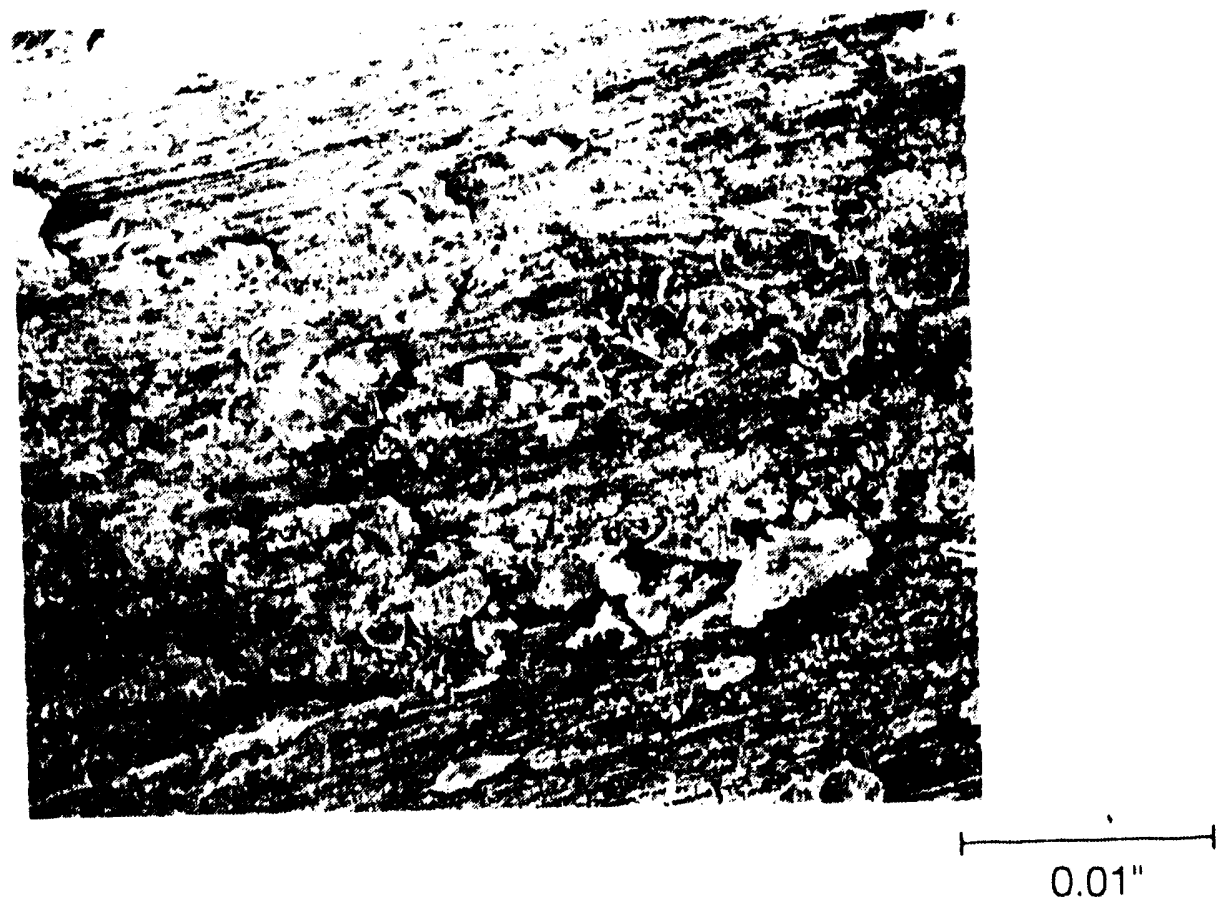

Figure 5. SEM photomicrograph of the vanadium tubing not fully cleaned by Nitradd process. Most of the rough oxide layer has been removed, but some particles still adhere to the surface. Increased cleaning time solved this problem satisfactorily. 

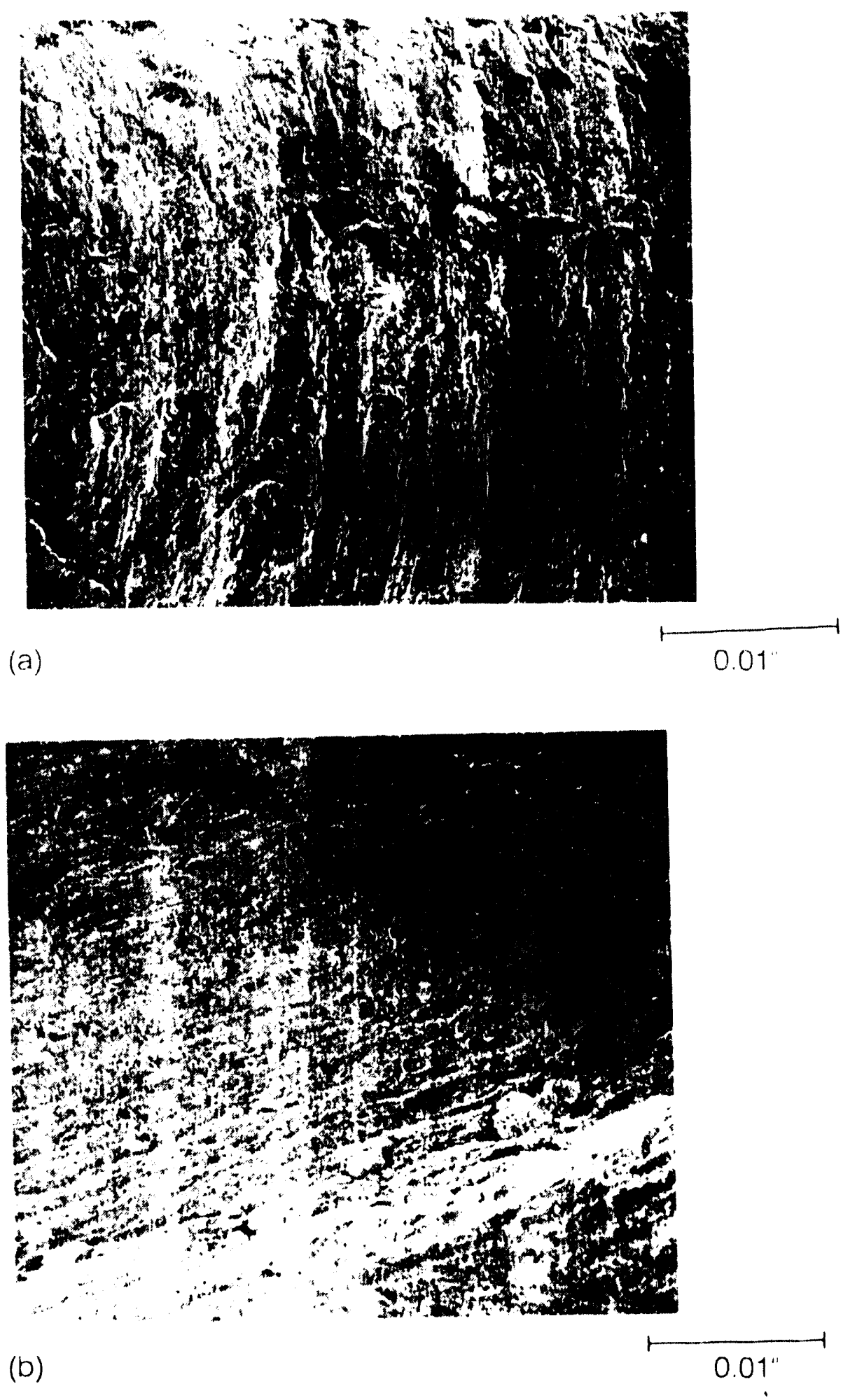

Figure 6. SEM photomicrographs of tubing cleaned at ASA-KCD. The Dynadet cleaned specimen (a) shows some of the loose particles of oxide to have been removed but the adherent layer of oxide at the vanadium surface to be unaffected. The aqua regia cleaned specimen (b) was found to be partially cleaned. With further process optimization aqua regia holds promise of success for cleaning vanadium tubing. 

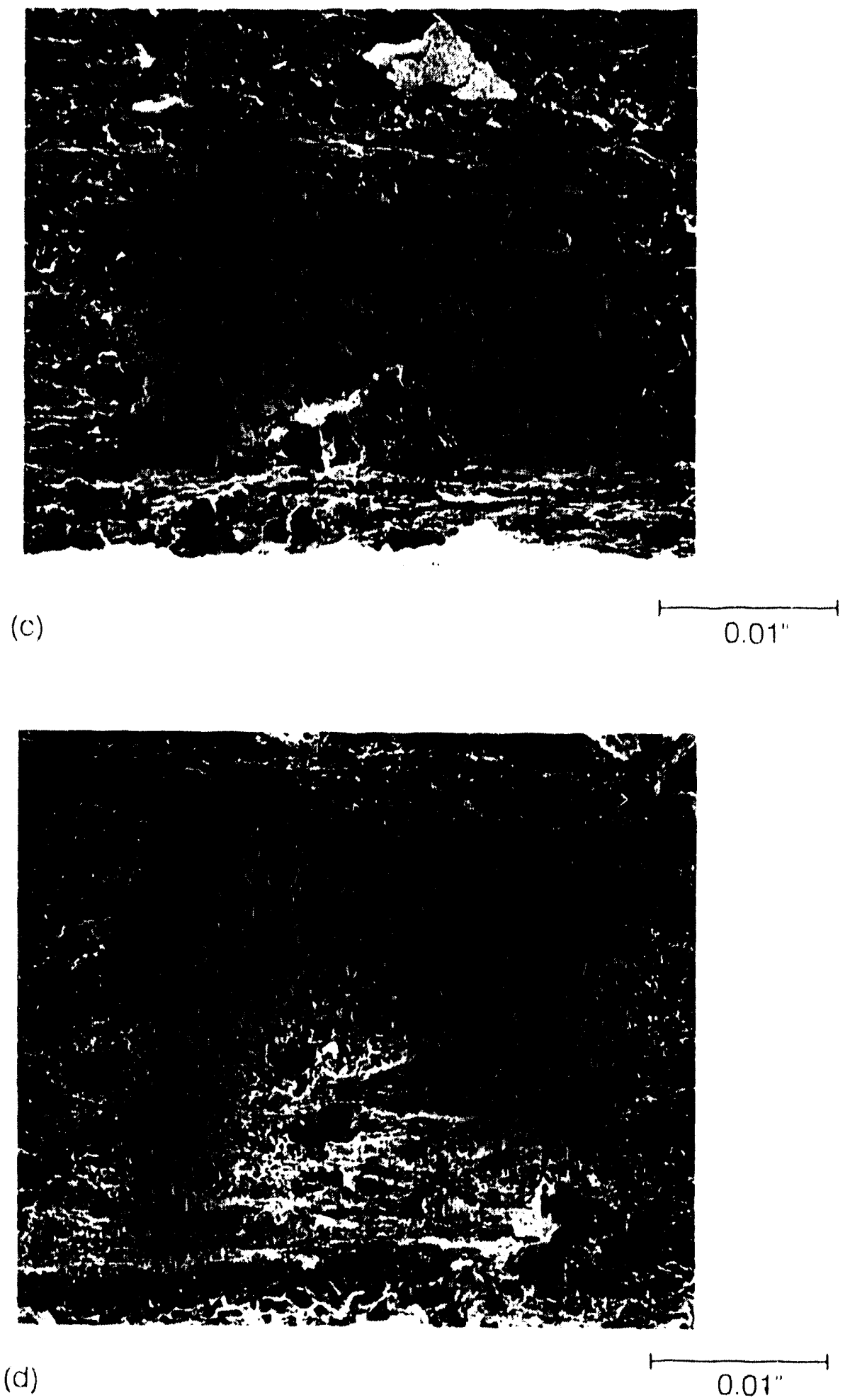

Figure 6 (cont.) The sodium hydroxide cleaned specimen (c) showed signs of chemical reaction with the tubing surface, but no satisfactory tube cleaning was found. The concentrated nitric acid cleaned specimen (d) was extremely overetched in appearance. This solution cut deep features into the wall of the vanadium tubing. 


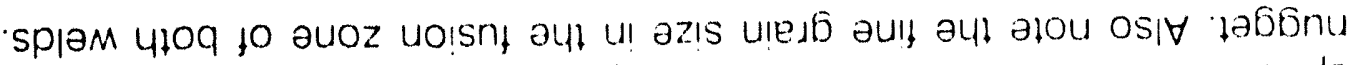

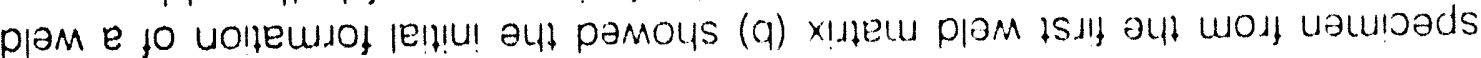

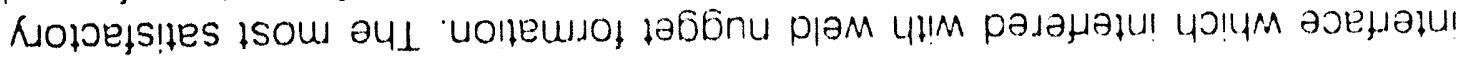

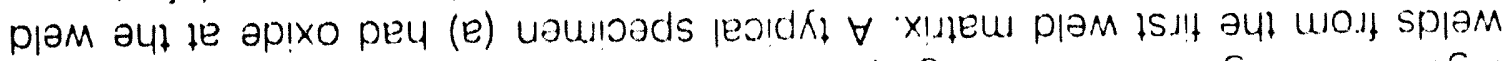

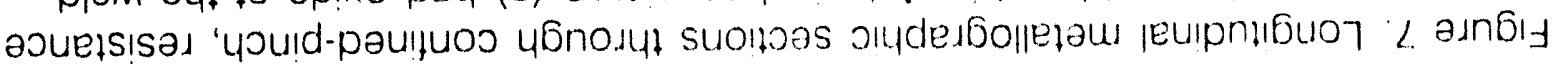

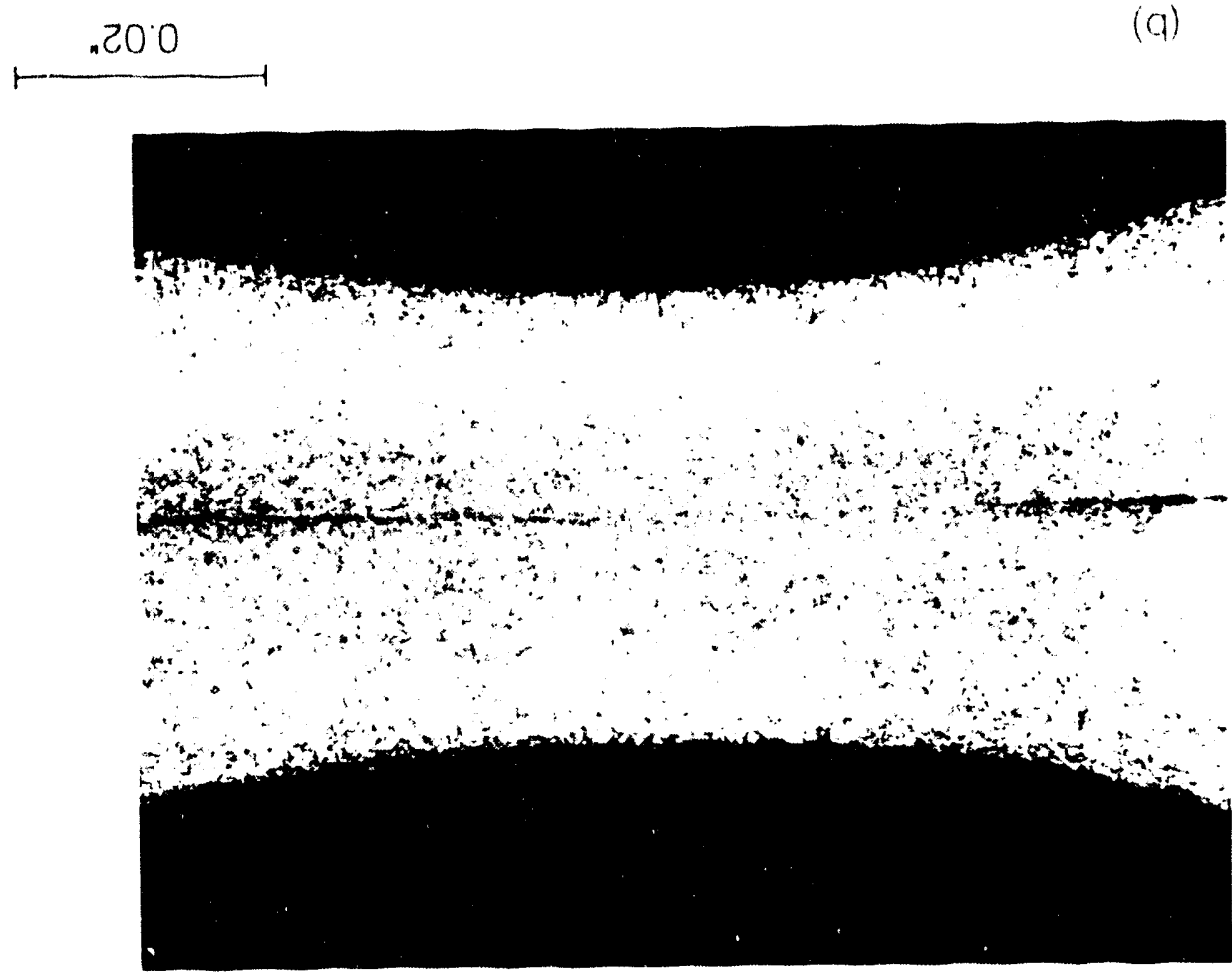

200

(e)

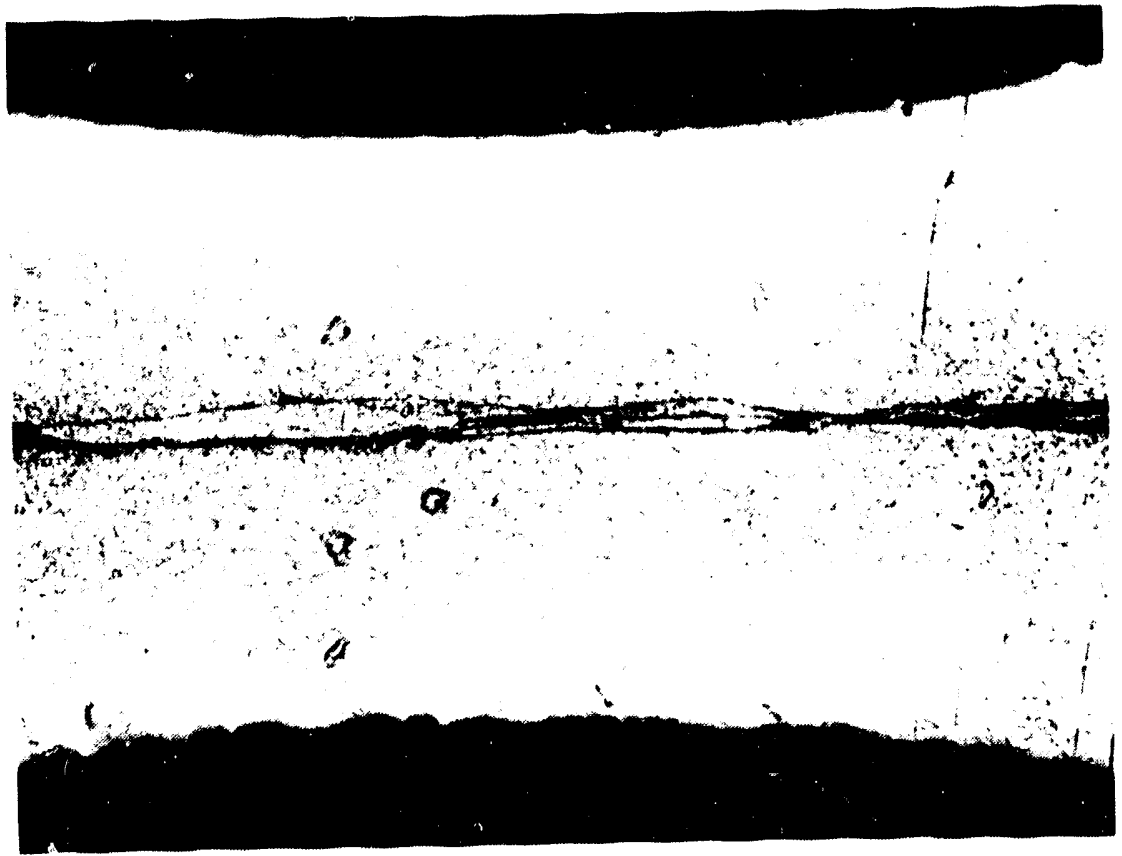




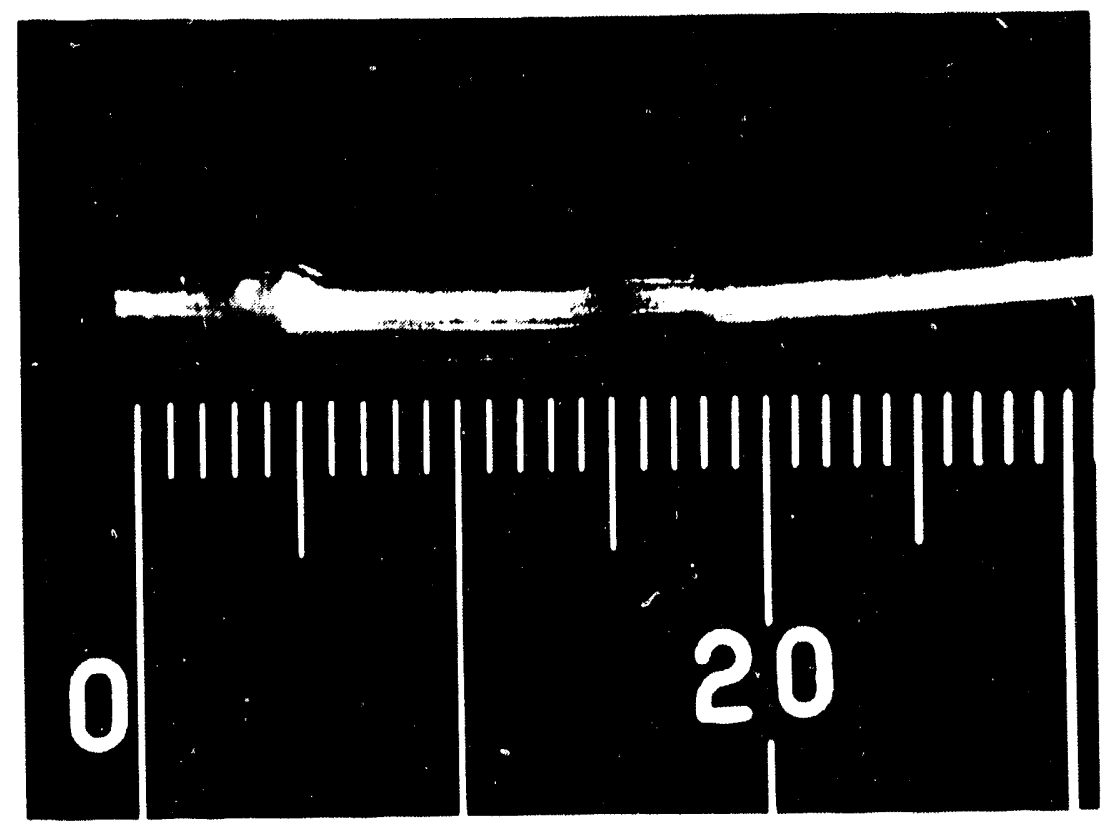

Figure 8. Macrograph showing a confined-pinch, resistance weld and the failure in the base tubing caused by burst testing. Note that no relation exists between the weld and falibe area

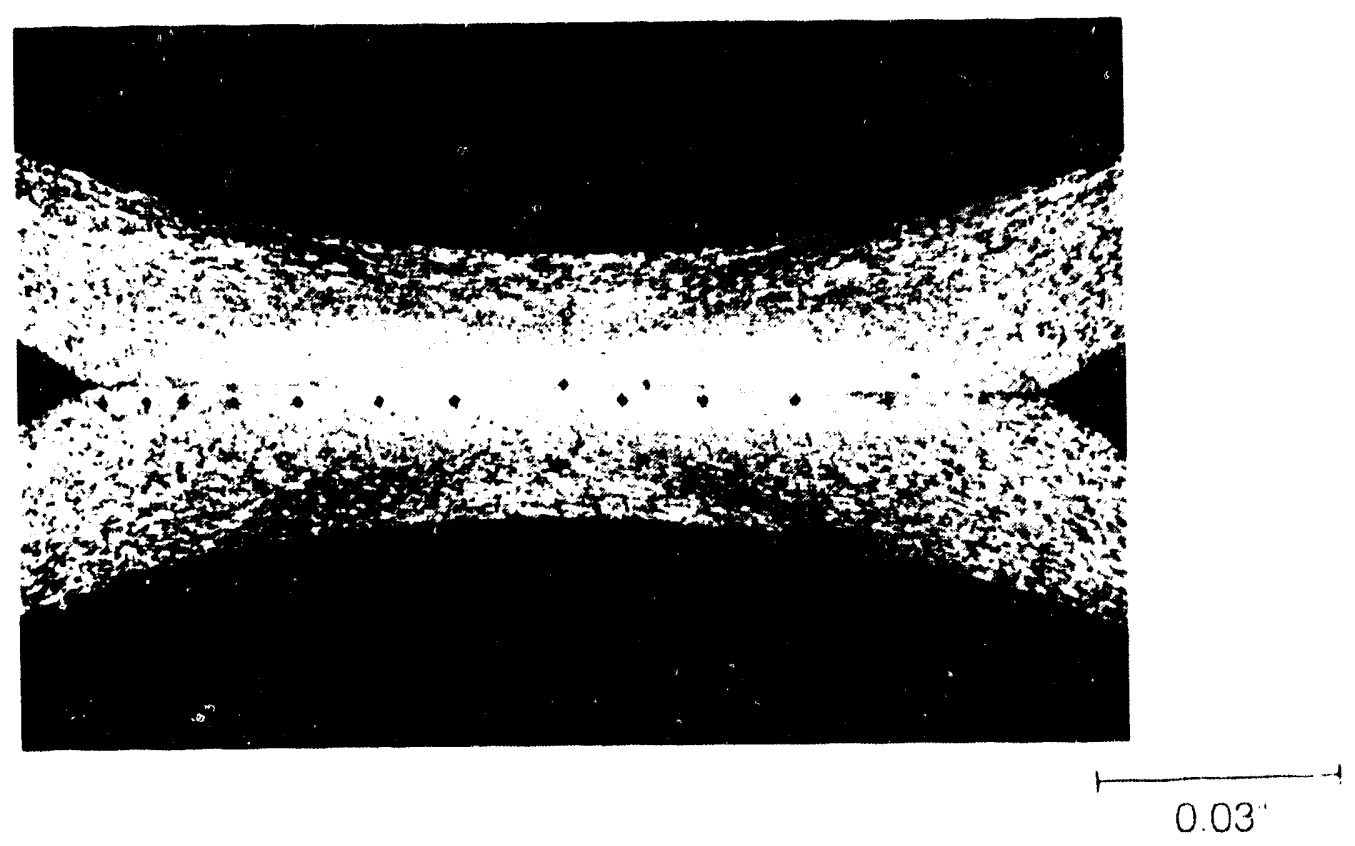

Figure 9 Me:alographic cross-section of confined-pinch, resistance weld from second matrx. This weld has a well-formed weld nugget that is approximately the times thicker than the original tube wall The weld is very fine grained due to the fast cooling rates durng solidfication and shows no signs of oxide contamination at the interface? 

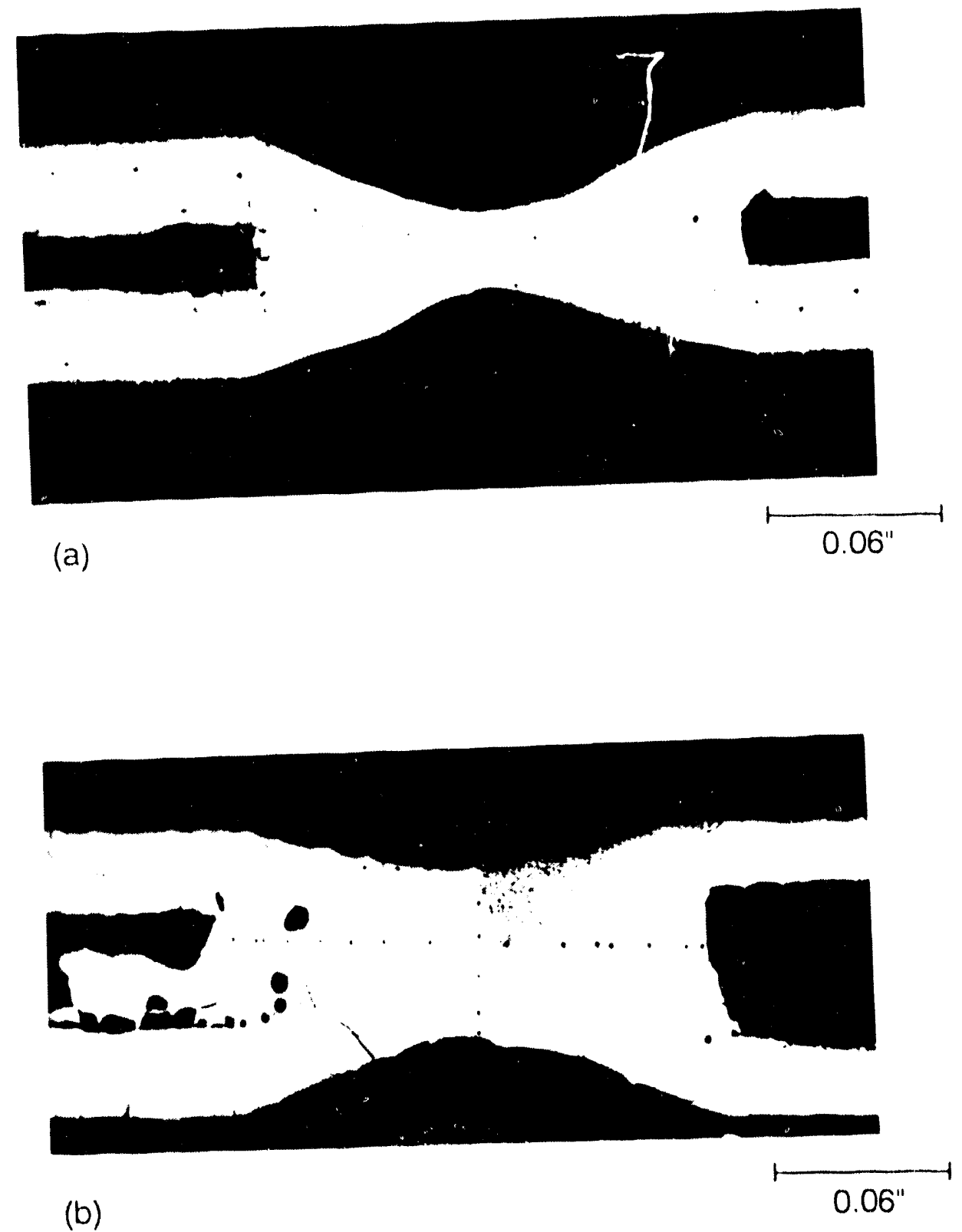

Figure 10. Metallographic cross-sections of GTAW - orbital weld head șeal welds. Weld shown in (a) had argon shielding and back-purging. The fusion zone grain size is very large although with cleaner tubing, the grain size would be still larger. Weld shown in (b) had argon shielding with a carbon dioxide back-purge. The fusion zone grain size is reduced since the carbide precipitation allowed nucleation of more grains. Also note the porosity in this weld caused by oxygen present in the weld metal due to the breakdown of carbon dioxide. 


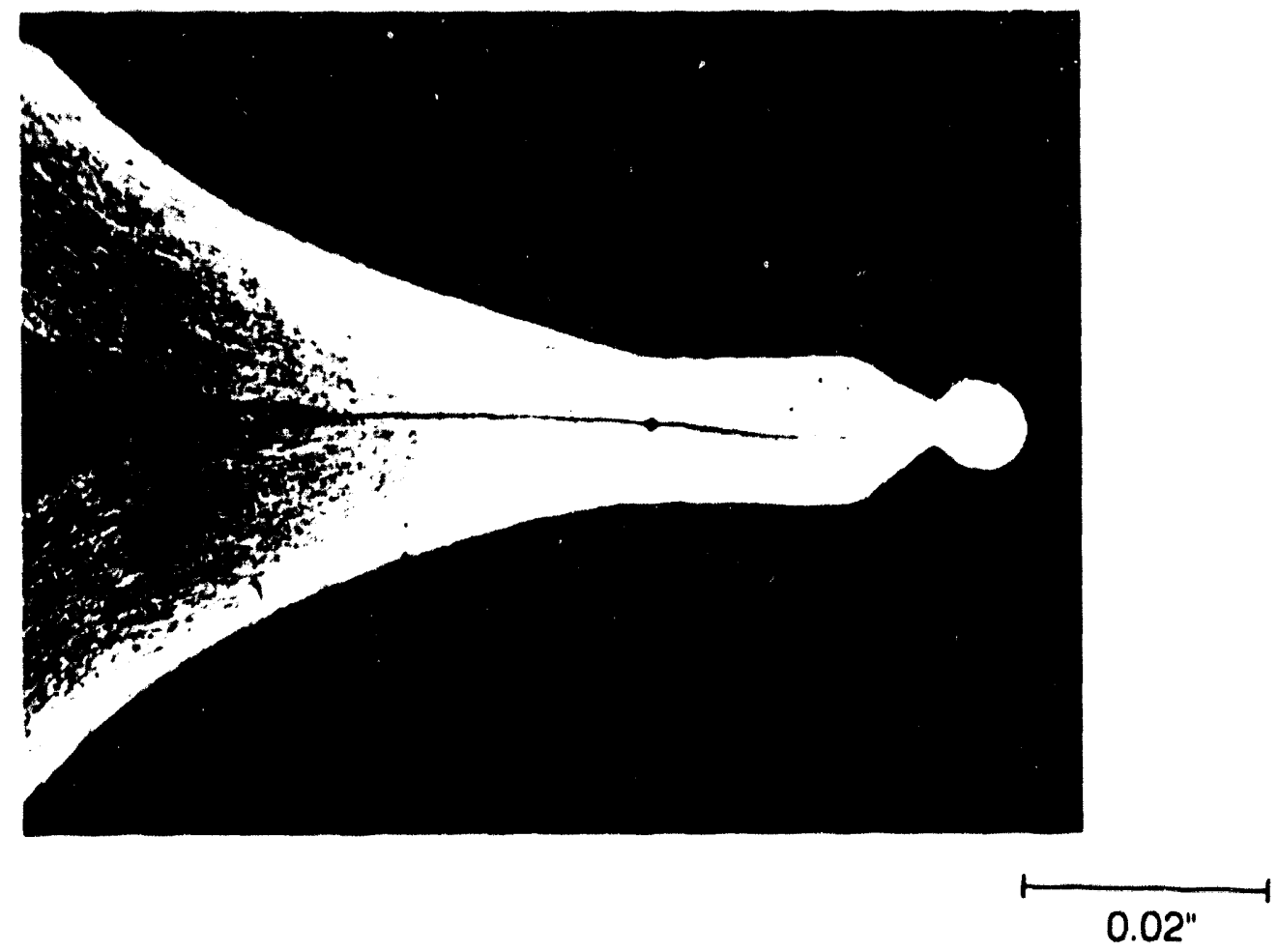

Figure 11. Metallurgical cross-section of mechanical crimp and GTA weld seal. The mechanical crimp is found to be many times larger than the weld affected area. Wall-thinning occurs from the point where the tube starts stretching from the crimping action up to the end of the crimp. This crimp shows a lap on the ID surface just below the crimp interface that has opened slightly because of mechanical deformation. 


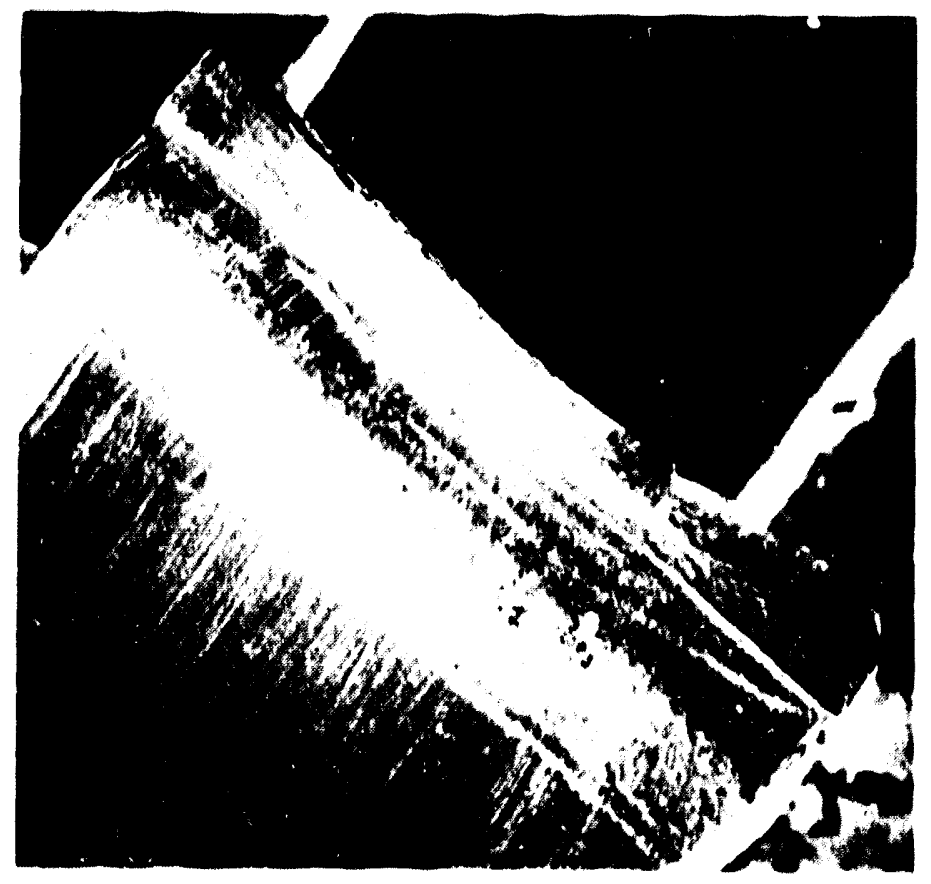

(a)
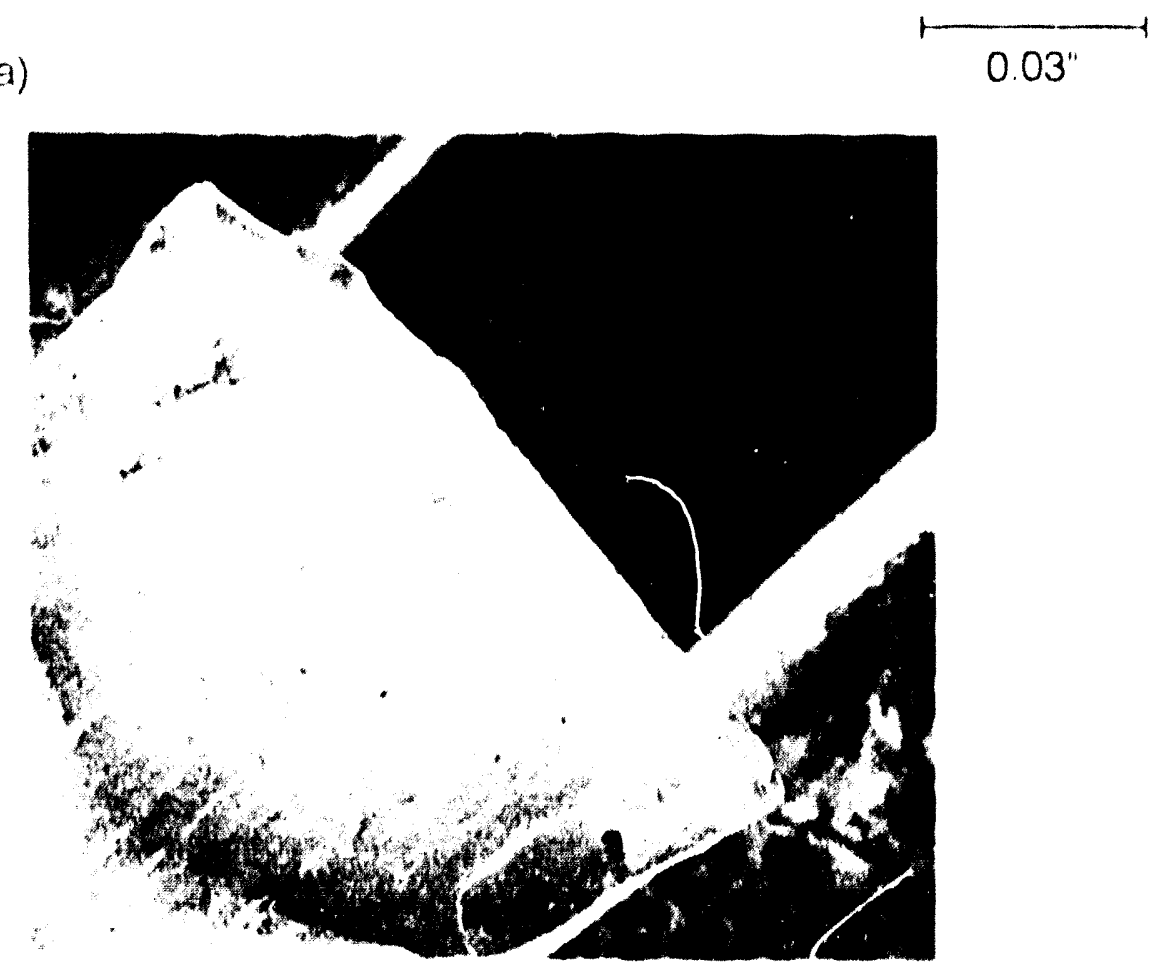

(b)

Figure 12. SEM photomicrograph of mechanically crimped tubes after burst testing. The typical failure in a seal side crimp (a) occurs at the area of thinnest wall in the crimp. This area is also a stress raiser due to the fairly sharp corner made by the crimping equipment. The typical failure on a throw-away side crimp (b) also occurs at the spot where the wall is thinnest. Note the more gradual crimu radius and thicker wall section as compared to the seal side crimp. These allow much higher burst pressures to be attained by these specimens. 

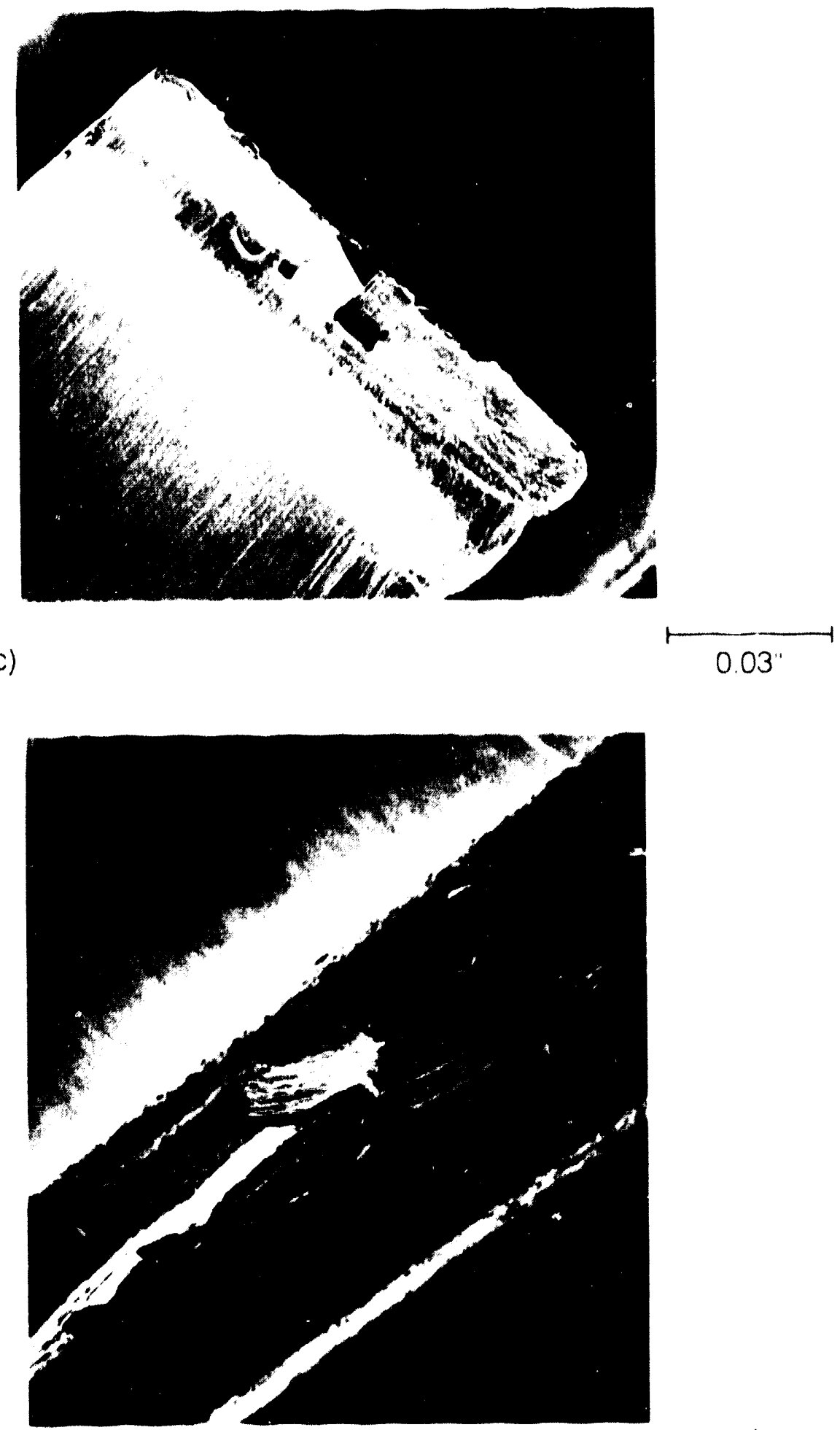

(d)

Figure 12 (cont.) The specimen that had a very low burst pressure (c) has a much different failure mode than other specimens. At higher magnification (d), it shows great ductility and the effects of the flaw running longitudinally to the tube drawing axis that caused the failure at low pressure 


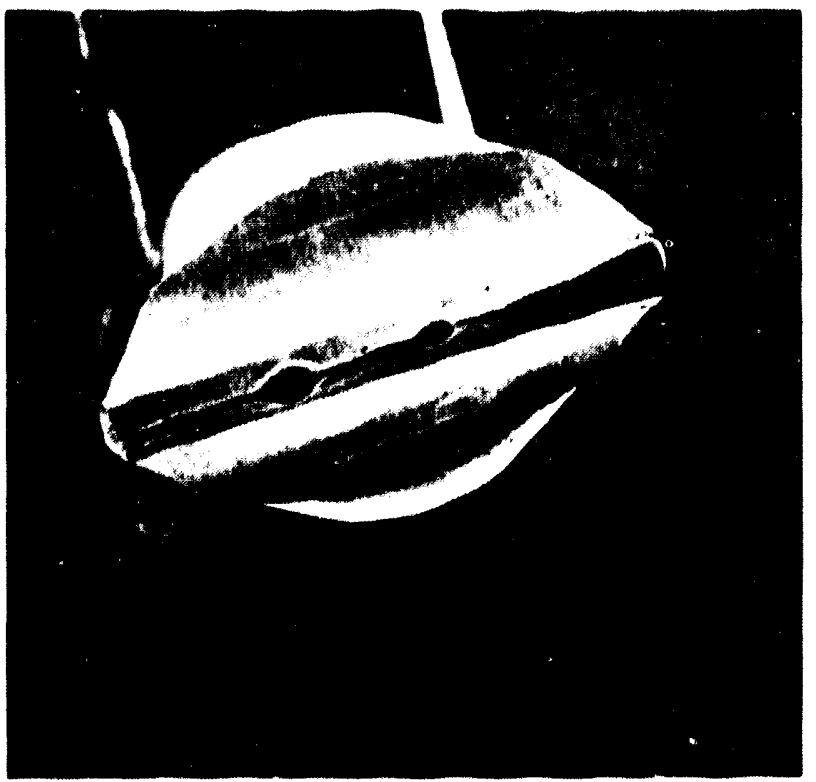

(a)
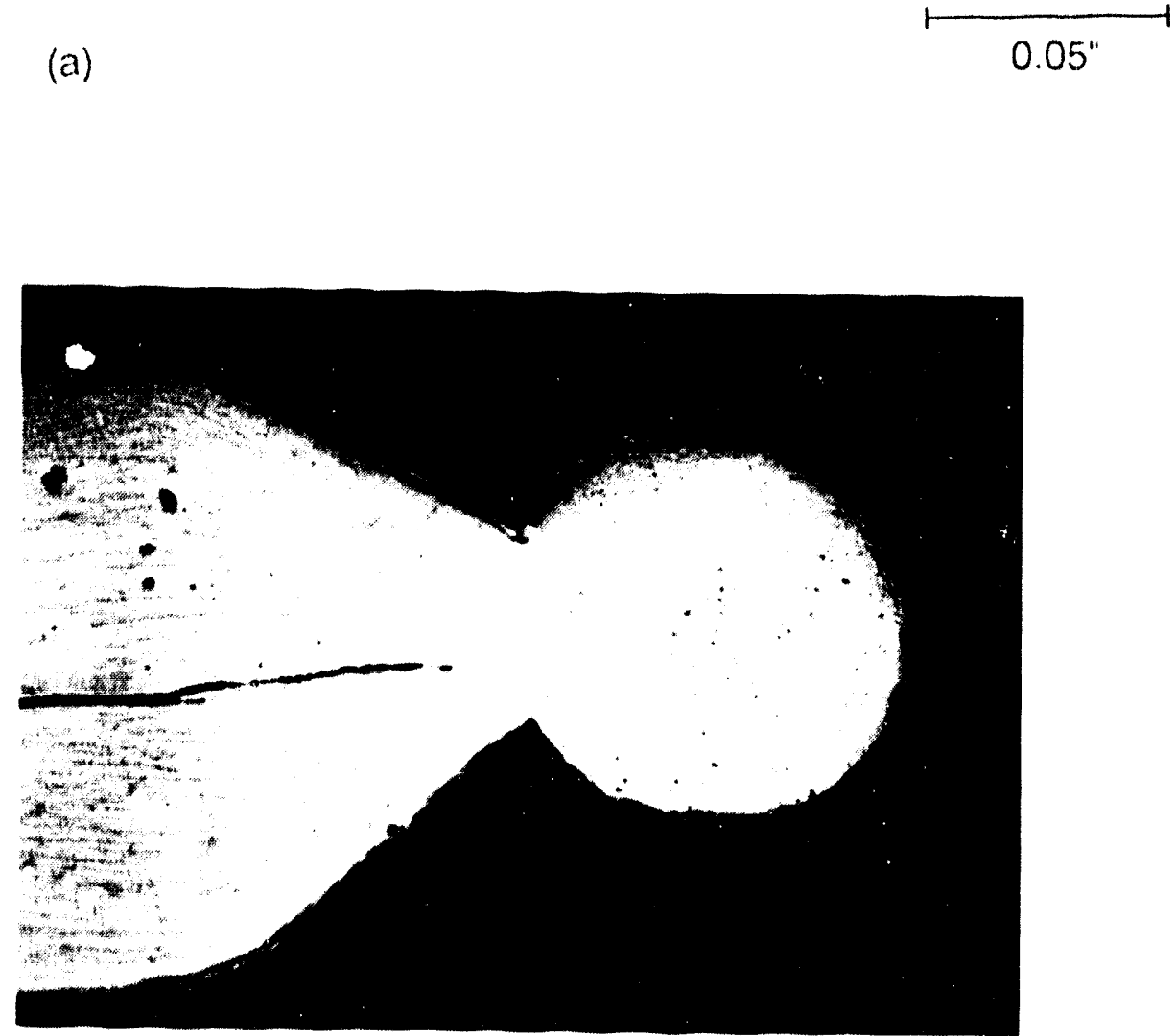

(b)

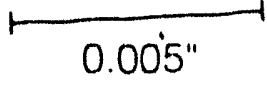

Figure 13. Views of the GTA seal weld used on mechanical crimps. A SEM photomicrograph (a) shows how small this weld is compared to the mechanically crimped area. The metallographic cross-section (b) shows the extremely small HAZ associated with this weld. 

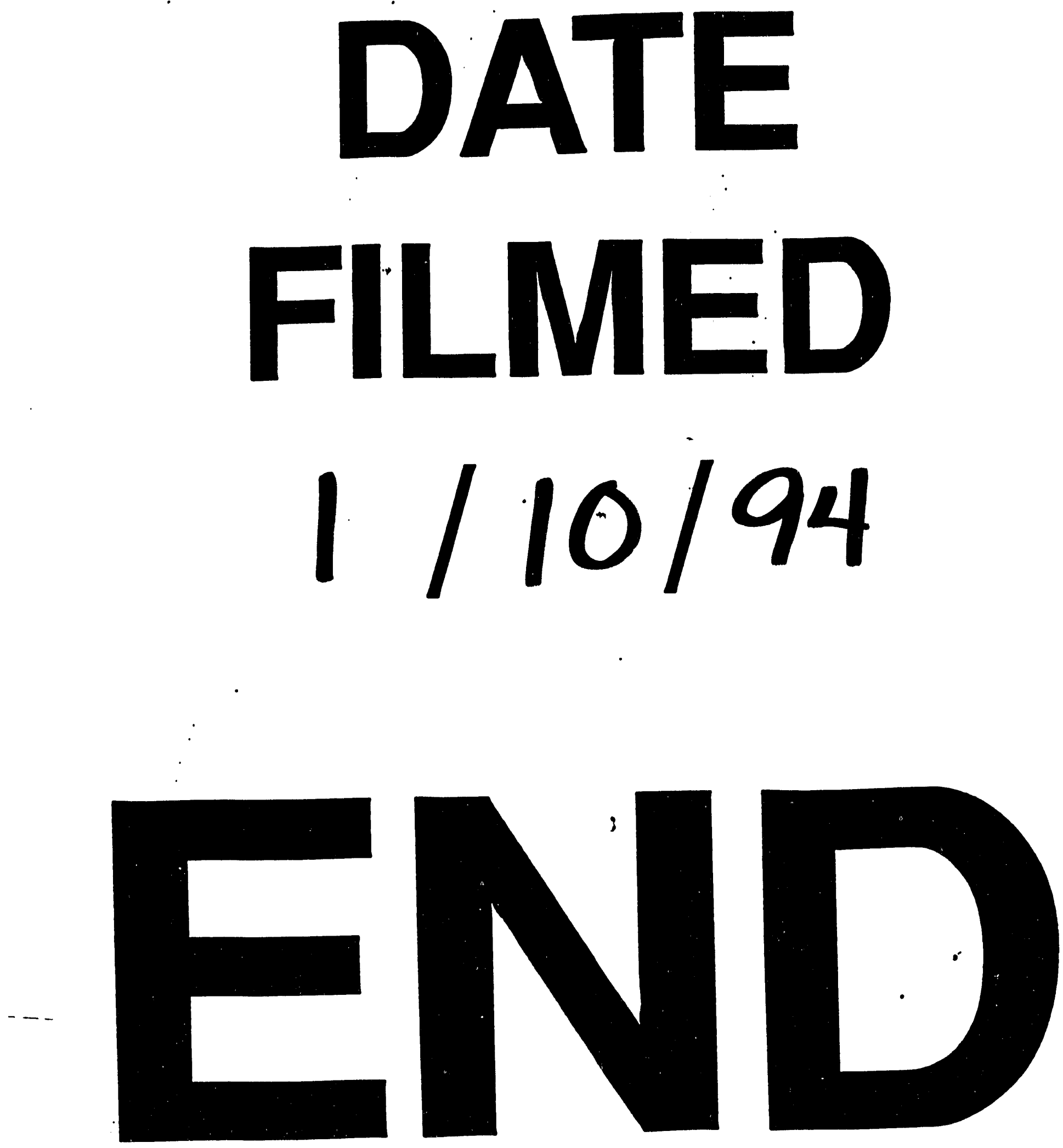


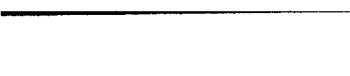

$\longrightarrow$
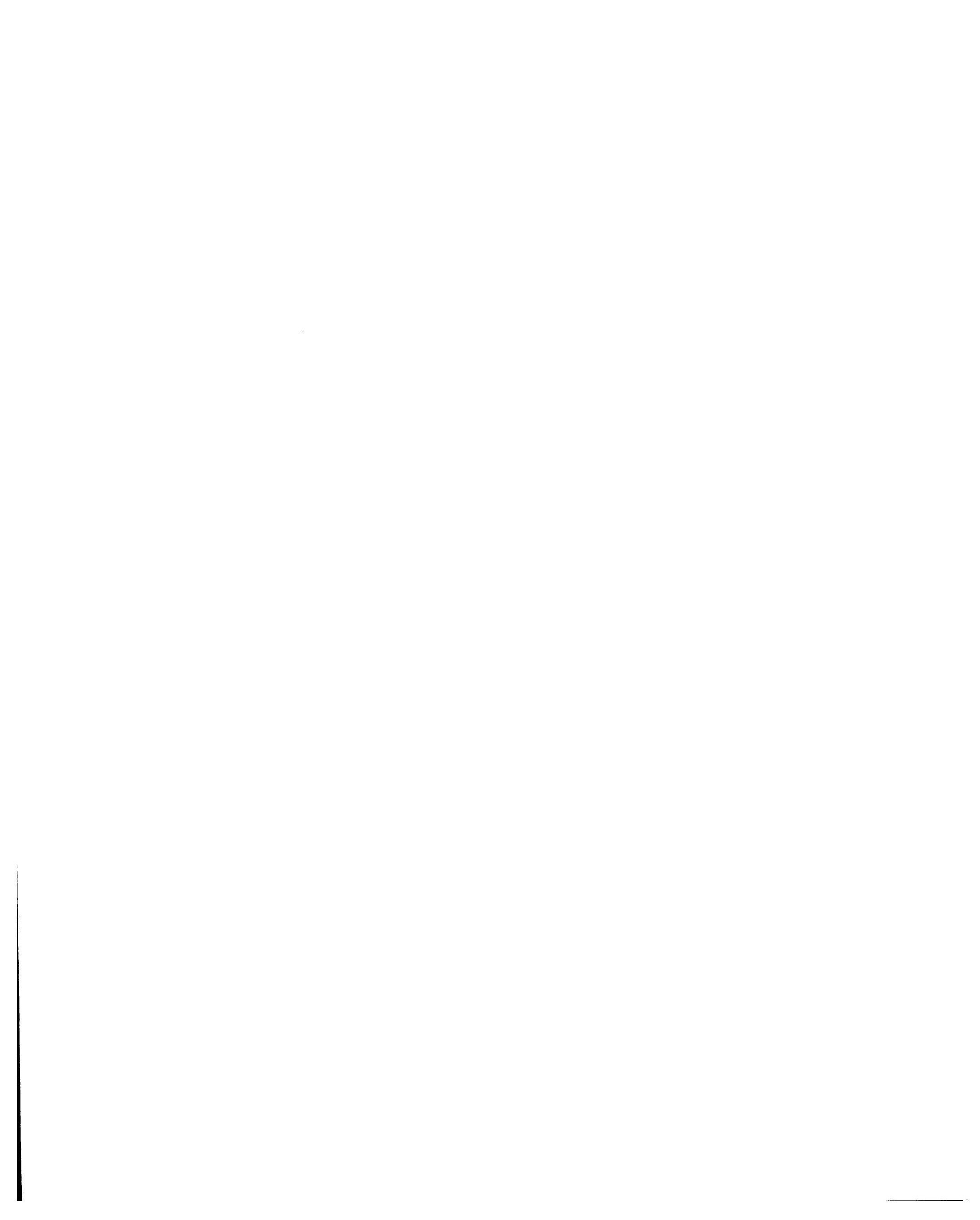